\section{Influence of tobacco use on postoperative opiate analgesia requirements in patients undergoing coronary artery bypass graft surgery}

TOBY N. WEINGARTEN • ELIZABETH A. ERIE • YU SHI • DARRELL R. SCHROEDER • MARTIN D. ABEL • DAVID O. WARNER
TOBY N. WEINGARTEN $(\bowtie) \bullet$ YU SHI • MARTIN D. ABEL • DAVID O. WARNER Department of Anesthesiology College of Medicine, Mayo Clinic 200 First Street, SW

Rochester, MN 55901 Phone: (507) 255-1612 Fax: (507) 255-6463 E-mail: weingarten.toby@mayo.edu

ELIZABETH A. ERIE

Mayo Medical Student

College of Medicine Mayo Clinic, Rochester, MN

DARRELL R. SCHROEDER

Department of Health Sciences Research (statistician) College of Medicine

Mayo Clinic, Rochester, MN

\begin{abstract}
Introduction. The objective of this study was to test the hypothesis that tobacco use status is independently associated with postoperative opioid requirements in patients undergoing coronary artery bypass grafting (CABG) when important demographic variables such as age and gender are taken into account.

Methods. A retrospective chart review of patients who underwent CABG surgery over a one year period at Mayo Clinic in Rochester, $M N$ was performed. Tobacco users $(N=69)$ were compared to nonusers $(N=345)$ with regards to opiate requirements and the occurrence of severe pain during the first 48 hours postoperatively. For comparison, all postoperative opiates were converted to oral morphine equivalents (OME). Adjusted analysis for age and gender was also performed.

Results. Tobacco users were younger than nonusers $(P<0.001)$, and a greater proportion of former users were male compared to never users $(P=0.003)$. Tobacco users had greater mean opiate requirements $401 \pm 284$ than nonusers $314 \pm 240$ mg OME, $(P=0.009)$. However, the association between tobacco use and greater postoperative opiate requirements lost significance after adjustment for age and gender. Tobacco use was not associated with increased risk of the development of severe pain $(P=0.51)$.

Conclusions. Although current tobacco users undergoing CABG surgery utilize more opioid analgesics in the first 48 hours following extubation than nonusers of tobacco, when adjusted for age and gender, tobacco use was not independently associated with differences in postoperative opioid use.
\end{abstract}

Key words: tobacco use, postoperative opiates, acute pain, coronary artery bypass surgery

\section{Introduction}

Nicotine can produce analgesia in both smokers and non-smokers, (1) and specifically produces modest postoperative analgesia in non-smokers, (2-4) but apparently not in smokers. (5) Chronic exposure to nicotine among tobacco users may also affect pain perception. For example, patients with chronic pain disorders who use tobacco report greater pain intensity and functional impairment compared with those who do not use tobacco. (6-8) Regarding acute pain, several studies have suggested that smokers have greater postoperative pain (9) and increased postoperative opioid requirements (1012) than nonsmokers. Creekmore et al. demonstrated that smokers undergoing coronary artery bypass graft surgery (CABG) required more postoperative opioids than nonsmokers (33\% greater opioid requirements adjusted for body mass index). (11) Limitations of these 
studies (small sample sizes, heterogenous surgical populations, and others) precluded meaningful adjustment for variables such as age (13-15) and gender $(16,17)$ which are known to strongly influence postoperative pain. Thus, the association between smoking and higher postoperative opiate requirements is unclear.

The objective of this study was to test the hypothesis that tobacco use status is independently associated with postoperative opioid requirements in patients undergoing CABG when important demographic variables such as age and gender are taken into account.

\section{Materials and Methods}

The Mayo Clinic Institutional Review Board approved this study. In accordance with Minnesota law, only patients that had provided preauthorization for the use of their medical record in research were included (>95\% of Mayo patients). Using the Mayo Clinic Cardiac Surgical Registry, we identified all patients that underwent CABG surgery via a primary sternotomy and had an endoscopically harvested saphenous vein graft during the time period of January $1^{\text {st }} 2007$ thru December $31^{\text {st }}$ 2007. This vein grafting procedure produces minimal incisional pain at the site of harvest. Exclusion criteria included lack of data regarding current self-reported smoking status (never, former, or current smoker), prolonged endotracheal intubation (more than 12 hours after skin closure), and cardiac re-operation or death within 48 hours of extubation. Because incisional pain from vessel donor sites could affect opioid requirements (18) patients that underwent radial artery harvest or open saphenous vein harvest were excluded. Patients receiving intraoperative supplementation of anesthesia with a ketamine infusion were also excluded because of the potential for residual analgesic effects. Patients who also underwent valvular replacement in addition to their CABG surgery were also included.

Information regarding each patient's tobacco use history (current user [wit- hin 30 days prior to surgery], former user, or never user), demographic and clinical variables, and intraoperative and postoperative opiate analgesics used in the first 48 hours postoperatively were recorded. To make comparison between opioid medications, all opioids were converted to oral morphine equivalents (table 1) using published dose equivalents for opiate analgesics guidelines. (19-22) Only one patient, a 68 year old male who was taking methadone $5 \mathrm{mg}$ three times a day for chronic face pain, was administered methadone in the postoperative period, a single $5 \mathrm{mg}$ oral dose. For this case methadone was converted to morphine equivalents using a 1:1 conversion ratio. Upon arrival to the intensive care unit, a fentanyl infusion was initiated at $0.5 \mathrm{mcg} / \mathrm{kg} / \mathrm{hr}$ and continued until extubation. Following extubation,

Table 1. Dose equivalents for opiate analgesics to oral morphine equivalents. (19-22)

\begin{tabular}{lll}
\hline \multicolumn{2}{l}{ Opiate Analgesic } & $\begin{array}{l}\text { Oral Morphine } \\
\text { Equivalents (mg) }\end{array}$ \\
\hline Intravenous fentanyl & $100 \mathrm{mcg}$ & 30 \\
\hline Intravenous sufentanil & $12 \mathrm{mcg}$ & 30 \\
\hline Intravenous hydromorphone & $1.5 \mathrm{mg}$ & 30 \\
\hline Intravenous morphine & $10 \mathrm{mg}$ & 30 \\
\hline Intravenous meperidine & $75 \mathrm{mg}$ & 30 \\
\hline Intravenous oxymorphone & $1 \mathrm{mg}$ & 30 \\
\hline Oral oxycodone & $20 \mathrm{mg}$ & 30 \\
\hline Oral hydrocodone & $20 \mathrm{mg}$ & 30 \\
\hline Oral methadone* & $1 \mathrm{mg}$ & 1 \\
\hline Oral tramadol & $50 \mathrm{mg}$ & 10 \\
\hline
\end{tabular}

* One patient received a single $5 \mathrm{mg}$ dose of methadone. This patient was a 68-year-old male that used methadone $5 \mathrm{mg}$ three times a day for chronic face pain. We chose a 1:1 conversion in this instance.

Table 2. Intraoperative and postoperative oral morphine equivalents $(\mathrm{mg})$ use by tobacco use status.

\begin{tabular}{|l|l|l|l|l|}
\hline & $\begin{array}{l}\text { Never User } \\
\mathrm{N}=138\end{array}$ & $\begin{array}{l}\text { Former } \\
\text { User } \\
\mathrm{N}=207\end{array}$ & $\begin{array}{l}\text { Current } \\
\text { User } \\
\mathrm{N}=69\end{array}$ & $\mathrm{P}$ \\
\hline Intra-operative & $639(303)$ & $639(302)$ & $611(253)$ & 0.7672 \\
\hline $\begin{array}{l}\text { 0-48 hours after } \\
\text { extubation }\end{array}$ & $293(217)$ & $329(254)$ & $401(284)$ & 0.0136 \\
\hline
\end{tabular}

Values are Mean (SD) typically, patients were administered intravenous fentanyl via a patient-controlled analgesia device until they could tolerate oral opiate medications and then were usually administered either Nursing staff regularly obtain pain scores from patients using a numeric rating pain scale from $0-10$, with 0 being no pain and 10 being maximal The use of nicotine replacement od was also noted.

Analysis. Statistical analysis was conducted using JMP (version 7.0.1, SAS Institute Inc., Cary, NC). Clinical and between groups using Student's t-test continuous variables and the chi-square test (or Fisher's exact test) for categorical variables. Initial analyses were oxycodone or tramadol. Patients also 
Table 3. Postoperative opioid requirements following coronary artery bypass surgery according to tobacco use status, age, and gender.

\begin{tabular}{llll}
\hline Patient characteristic & $\begin{array}{l}\text { Effect estimate* } \\
\text { (mg OME) }\end{array}$ & $\begin{array}{l}\text { 95\% Confidence Interval } \\
\text { (mg OME) }\end{array}$ & P \\
\hline Current tobacco use & +6.2 & $-25.6,+38.0$ & 0.70 \\
\hline Age (decade of life) & -77.5 & $-99.6,-55.4$ & $<0.0001$ \\
\hline Female gender & -53.0 & $-79.5,-26.5$ & 0.0001 \\
\hline
\end{tabular}

OME = Oral morphine equivalents. * Effect estimate corresponds to mean increase or decrease in OME mg associated with the given characteristic

Table 4. Logistic regression model of the occurrence of post-operative severe pain within the first $\mathbf{4 8}$ hours.

\begin{tabular}{|c|c|c|c|c|c|c|}
\hline \multirow[t]{2}{*}{ Patient characteristic } & \multicolumn{3}{|c|}{ Univariate Analysis } & \multicolumn{3}{|c|}{ Multivariate Analysis } \\
\hline & Odds Ratio & $95 \% \mathrm{Cl}$ & $P$ & Odds Ratio & $95 \% \mathrm{Cl}$ & $P$ \\
\hline Age (decade of life) & 0.10 & $0.03,0.27$ & $<0.0001$ & 0.09 & $0.03,0.26$ & $<0.0001$ \\
\hline Gender & & & 0.180 & & & 0.336 \\
\hline Male & 1.00 & - & & 1.00 & - & \\
\hline Female & 1.41 & $0.85,2.29$ & & 1.29 & $0.77,2.13$ & \\
\hline Tobacco Use & & & 0.512 & & & 0.398 \\
\hline Current User & 1.00 & - & & 1.00 & - & \\
\hline Current Non-user & 0.83 & $0.47,1.48$ & & 1.30 & $0.71,2.46$ & \\
\hline
\end{tabular}

performed with patients categorized into three groups (current, past tobacco users, and never tobacco users). Because past tobacco users and never tobacco users had similar postoperative opiate requirements (see below), these two groups were combined for subsequent multivariate analysis. Analysis of covariance (ANCOVA) was conducted for post-operative opiate requirements using age, gender and tobacco use as covariates. Pain was considered to be severe if the numeric pain score provided by a patient was 7 or greater. $(23,24)$ The association between current tobacco use and the risk of experiencing an episode of severe pain was determined with logistic regression. A subsequent multivariate analysis logistic regression model for the development of severe pain was also constructed using age, gender and tobacco use as covariates. In all cases a $P$ value of $<0.05$ was considered significant.

\section{Results}

Four hundred fourteen (414) patients underwent coronary artery bypass surgery and received an endoscopically harvested saphenous vein graft. In this cohort, 69 patients reported current use of tobacco products (within 30 days prior to the surgery). Fifty-eight of the tobacco users used cigarettes as their primary tobacco product, with the remaining using either chewing tobacco or cigars. Tobacco users were younger than non-users $(61 \pm 11$ vs $71 \pm 10$ years, $P<0.001)$, but had similar gender distribution (78\% and $76 \%$ male among users and non-users, respectively, $P=0.72$ ). Of the nonusers, 138 reported never using tobacco products and 207 reported prior use. Of the former users, $90 \%$ reported not using tobacco products for greater than one year and $71 \%$ reported not using for greater than 10 years. There was no age difference between former and never users $(70 \pm 10$ vs $70 \pm 11$ years, $P=0.71$ ), but a greater proportion of former smokers were male (82\% vs $67 \%, P=0.003$ ). The number of patients that also underwent a valvular procedure during CABG similar was similar between tobacco users and nonusers (28\% vs $27 \%, P=0.210$ ). Cardiopulmonary bypass times were similar among tobacco users and nonusers $(95 \pm 34$ vs $94 \pm 32$ minutes, $P$ $=0.83$ ).

There was no significant difference in the amount of intraoperative opioids given to the three groups (table 2). Current tobacco users received more opioids than non-users in the first 48 hours after extubation (401 $\pm 284 \mathrm{mg} \mathrm{OME} \mathrm{vs} 314$ $\pm 240 \mathrm{mg}$ OME, $\mathrm{P}=0.009$ ). There was a trend for former users to use more opioids than never users (table 2), but this did not reach statistical significance. However, after adjustment for demographic differences (age and gender) in multivariable analysis, the association between current tobacco 
use and opioid use in the 48 hours after extubation was no longer significant (table 3). Post-operatively, 25 current tobacco users received therapy for nicotine dependence (22 received nicotine replacement, 6 received varenicline, and 3 patients receiving both). There was no difference in total 48 hour opioid used between tobacco users that received therapy for nicotine dependence compared to those that did not $(420 \pm 275 \mathrm{mg}$ oral morphine equivalents [OME] vs $397 \pm 291 \mathrm{mg}$ $\mathrm{OME}, \mathrm{P}=0.75$ ). Severe pain (reported pain scale $>7 / 10$ ) was reported at least once by 82 patients (20\%) in the first 48 hours after extubation. The odds of experiencing severe pain were not influenced by tobacco use with either univariate or multivariate analysis (table 4), but were greater in younger patients.

\section{Discussion}

The major finding of this study is that current tobacco users undergoing CABG surgery utilize more opioid analgesics in the first 48 hours following extubation than nonusers of tobacco. However, when adjusting for age and gender, tobacco use was not independently associated with differences in postoperative opioid use. A secondary finding of this study is that tobacco users are not at increased risk for the development of severe postoperative pain.

Chronic exposure to nicotine and other tobacco constituents is associated with an increased prevalence of chronic painful conditions in many studies. $(25,26)$ Among those with chronic pain, smokers report greater pain intensity and functional impairment. $(7,8)$ Multiple mechanisms may explain this association, including changes in acetylcholine receptor distribution or function in response to chronic nicotine exposure. On the other hand, nicotine itself can produce analgesia when administered acutely, both in smokers and non smokers, so that the overall effects of tobacco use on pain sensitivity appears to be complex and multi-factorial. (1) Creekmore et al. found that patients undergoing $\mathrm{CABG}$ surgery demonstrated that smokers had a $23 \%$ greater opioid requirement in the first 48 postsurgical hours compared with a group of former and never smokers. (11) The magnitude of the increased opioid requirement was very similar to our findings (tobacco users used $22 \%$ more post-operative opioids than non-users). However, factors other than tobacco use status may affect postoperative opioid requirements, including patient characteristics such as age, gender, and surgical procedural characteristics. (15) For example, multiple studies show that postoperative pain and opiate requirements are inversely related to age, (13-15) and less in female patients. $(16,17)$ Results from our multivariable analysis confirm these previous observations that age and gender were independently associated with postoperative opiate use. The younger age of tobacco users in our study reflect findings published by the Centers for Disease Control which shows that smoking rates are much lower among Americans over 65 years of age (8.3\%) compared to the general population (19.8\%). (27) Thus, the differences in opioid requirements associated with tobacco use status can be explained in part because current users were younger.

In addition to not adjusting for age and gender, the Creekmore et al. study did not provide data regarding surgical characteristics that may have influenced postoperative pain. In order to minimize variations in surgical stimulus, we limited our cohort to patients that underwent endoscopically harvested saphenous vein grafts as it was our clinical impression that radial artery harvest and open saphenous vein harvest result in significantly more postoperative pain, and internal mammary artery harvest does not contribute more pain other than that associated with sternotomy.

Other studies have found increased opioid consumption after surgical procedures in smokers. Berge et al. found that following third molar extraction, those smoking more than 10 cigarettes a day used significantly more acetaminophen/codeine tablets compared with non-smokers and light smokers, although the difference was modest (mean of 0.6 tablets). (10) In another study, female former and current smokers used more opioid analgesics than female never-smokers following obstetric and gynecologic surgery. (12) However, like the Creekmore study, neither study attempted to analyze possible covariates that might influence opioid consumption. Details of adjunctive techniques such as regional analgesia were not provided, nor was the level of analgesia achieved reported. In a general surgical population, smokers reported higher pain scores both before and after surgery but did not experience greater increases in pain postoperatively compared with nonsmokers, (9) although in this study pain was only a secondary endpoint, opioid consumption was not measured, and a wide range of surgical procedures was included. Thus, our study is not directly comparable, but we did not find that tobacco users were at increased risk of severe postoperative pain.

Our study had several significant limitations, including all the inherent limitations of a retrospective study. It also relied on patient self-report of tobacco use. Although such reports are generally reliable (28) there is the possibility that some of the non-users were actually using tobacco. Intraoperative management of anesthesia, including opioid administration, was not standardized, although a standardized regimen is followed in our cardiac anesthesia practice, as reflected by similar use of intraoperative opioids among all groups. Postoperative pain management was not standardized which introduces potential practice management differences as a source of bias. Furthermore, 25 tobacco users received therapy for nicotine withdrawal (nicotine replacement and/or varenicline), although we did not find an association between these therapies and opioid use. We did not attempt to exclude patients that used sustained release or long acting opiate formulations prior to 
surgery because this information was not always available from chart review. Because opioid tolerance increases postoperative opiate requirements 15 , potential differences between groups could have introduced bias. Data on the quantity or duration of tobacco use was also not available, and it has been suggested that heavy smokers have higher postoperative opiate require- ments. (10) We studied only one type of surgery, which is an experimental strength. However, these findings may not apply to other surgical procedures, including those examined in the prior studies reviewed. Finally, our institution is a major referral center and our results may not generalize to community based patients.

In conclusion, tobacco users undergo- ing CABG surgery receive more opioids postoperatively than non-users, but this is primarily a function of the interactions between tobacco use and other factors known to influence postoperative opioid requirements, specifically younger age and male gender. Studies of how tobacco use affects postoperative pain must adjust for other clinical variables that influence postoperative pain.

\section{REFERENCES}

1. Girdler SS, Maixner W, Naftel HA, Stewart PW, Moretz RL, Light KC. Cigarette smoking, stress-induced analgesia and pain perception in men and women. Pain 2005;114(3):372-85.

2. Flood P, Daniel D. Intranasal nicotine for postoperative pain treatment. Anesthesiology 2004;101(6):1417-21.

3. Habib AS, White WD, El Gasim MA, Saleh G, Polascik TJ, Moul JW, et al. Transdermal nicotine for analgesia after radical retropubic prostatectomy. Anesth Analg 2008;107(3):999-1004.

4. Hong D, Conell-Price J, Cheng S, Flood P. Transdermal nicotine patch for postoperative pain management: a pilot dose-ranging study. Anesth Analg 2008;107(3):1005-10.

5. Turan A, White PF, Koyuncu O, Karamanliodlu B, Kaya G, Apfel CC. Transdermal nicotine patch failed to improve postoperative pain management. Anesth Analg 2008;107(3):1011-7.

6. Vogt MT, Hanscom B, Lauerman WC, Kang JD. Influence of smoking on the health status of spinal patients: The National Spine Network Database. Spine 2002;27:313-19.

7. Weingarten TN, Iverson BC, Shi Y, Schroeder DR, Warner DO, Reid KI. Impact of Tobacco Use on the Symptoms of Painful Temporomandibular Joint Disorders. Pain 2009; in press.

8. Weingarten TN, Podduturu VR, Hooten WM, Thompson JM, Luedtke CA, Oh TH. Impact of Tobacco Use in Patients Presenting to a Multidisciplinary Outpatient Treatment Program for Fibromyalgia. Clin J Pain 2009;25(1):39-43.

9. Warner DO, Patten CA, Ames SC, Offord K, Schroeder D. Smoking behavior and perceived stress in cigarette smokers undergoing elective surgery. Anesthesiology 2004;100(5):1125-37.

10. Berge TI. Pattern of self-administered paracetamol and codeine analgesic consumption after mandibular third-molar surgery. Acta Odontol Scand 1997;55(5):270-6

11. Creekmore FM, Lugo RA, Weiland KJ. Postoperative opiate analgesia requirements of smokers and nonsmokers. Ann Pharmacother 2004;38(6):949-53.

12. Woodside JR. Female smokers have increased postoperative narcotic requirements. J Addict Dis 2000;19(4):1-10.

13. Gagliese L, Jackson M, Ritvo P, Wowk A, Katz J. Age is not an impediment to effective use of patient-controlled analgesia by surgical patients. Anesthesiology 2000;93(3):601-10.

14. Macintyre PE, Jarvis DA. Age is the best predictor of postoperative morphine requirements. Pain 1996;64(2):357-64.

15. Ready LB. Acute pain: lessons learned from 25,000 patients. Reg Anesth Pain Med 1999;24(6):499-505.

16. Joels CS, Mostafa G, Matthews BD, Kercher KW, Sing RF, Norton HJ, et al. Factors affecting intravenous analgesic requirements after colectomy. J Am Coll Surg 2003;197(5):780-5.

17. Chia YY, Chow LH, Hung CC, Liu K, Ger LP, Wang PN. Gender and pain upon movement are associated with the requirements for postoperative patient-controlled iv analgesia: a prospective survey of 2,298 Chinese patients. Can J Anaesth 2002;49(3):249-55.

18. Morris RJ, Butler MT, Samuels LE. Minimally invasive saphenous vein harvesting. Ann Thorac Surg 1998;66(3):1026-8.

19. Management of Cancer Pain; Clinical Practice Guideline Number 9. Agency for Health Care Policy and Research Publication No. 94-0592. U.S. Dept. of Health and Human Services, 1994.

20. Principles of Analgesic Use in the Treatment of Acute Pain and Cancer Pain. 4th edition ed. Skokie, Illinois: American Pain Society, 1999.

21. Fudin J, Toledo-Binette C, Kupiak DM, Johnston KR, Smith HS. Quicker dosage adjustment for transdermal fentanyl. Am J Health Syst Pharm 1997;54(1):87-8.

22. Zech DF, Grond SU, Lynch J, Dauer HG, Stollenwerk B, Lehmann KA. Transdermal fentanyl and initial dose-finding with patient-controlled analgesia in cancer pain. A pilot study with 20 terminally ill cancer patients. Pain 1992;50(3):293-301. 
23. Bodian CA, Freedman G, Hossain S, Eisenkraft JB, Beilin Y. The Visual Analog Scale for Pain: Clinical Significance in Postoperative Patients. Anesthesiology 2001;95(6):1356-61.

24. Serlin RC, Mendoza TR, Nakamura Y, Edwards KR, Cleeland CS. When is cancer pain mild, moderate or severe? Grading pain severity by its interference with function. Pain 1995;61(2):277-84.

25. Andersson H, Ejlertsson G, Leden I. Widespread musculoskeletal chronic pain associated with smoking. An epidemiological study in a general rural population. Scand J Rehabil Med 1998;30(3):195-91.

26. John U, Hanke M, Meyer C, Volzke H, Baumeister SE, Alte D. Tobacco smoking in relation to pain in a national general population survey. Prev Med 2006;43:477-81.

27. Center for Disease Control. Cigarette Smoking Among Adults - United States, 2007. Morbidity and Mortality Weekly Report 2008:1221-6.

28. Patrick DL, Cheadle A, Thompson DC, Diehr P, Koepsell T, Kinne S. The validity of self-reported smoking: a review and meta-analysis. Am J Public Health 1994;84(7):1086-93. 